\title{
Development and biopharmaceutical evaluation of extended release formulation of tramadol hydrochloride based on osmotic technology
}

PRAMOD KUMAR

SANJAY SINGH

BRAHMESHWAR MISHRA

Department of Pharmaceutics Institute of Technology Banaras Hindu University Varanasi-221005, U.P. India
Extended release formulation of tramadol hydrochloride (TRH) based on osmotic technology was developed and evaluated. Target release profile was selected and different variables were optimized to achieve it. Formulation variables such as the level of swellable polymer, plasticizer and the coat thickness of semipermeable membrane (SPM) were found to markedly affect drug release. TRH release was directly proportional to the levels of plasticizer but inversely proportional to the levels of swellable polymer and coat thickness of SPM. Drug release from developed formulations was independent of $\mathrm{pH}$ and agitation intensity but dependent on osmotic pressure of the release media. In vivo study was also performed on six healthy human volunteers and various pharmacokinetic parameters $\left(c_{\max }, t_{\max }, A U C_{0-24}, M R T\right)$ and relative bioavailability were calculated. The in vitro and in vivo results were compared with the performance of two commercial TRH tablets. The developed formulation provided more prolonged and controlled TRH release compared to the marketed formulation. In vitro-in vivo correlation (IVIVC) was analyzed according to the Wagner-Nelson method. The optimized formulation (batch IVB) exhibited good IVIV correlation $(R=0.9750)$. The manufacturing procedure was found to be reproducible and formulations were stable over 6 months of accelerated stability testing.

Keywords: tramadol, extended release, osmotic pressure, swellable polymer, in vitro-in vivo correlation

Oral ingestion has been the most convenient and commonly used route of drug administration because of its flexibility and dosage form design (1). In the immediate release (IR) dosage form, there is little or no control of drug release from the dosage form, which often results in constantly changing, unpredictable, and often sub- and supra-the-

\footnotetext{
*Correspondence; e-mail: pramod_79kumar@rediffmail.com; pramod_80kumar@yahoo.co.uk
} 
rapeutic plasma concentrations (2). Controlled release (CR) systems have been introduced to overcome the drawback associated with IR dosage forms. Among the various CR formulations available, per-oral controlled release (CR) holds the major market share because of its advantages such as ease of administration and better patient compliance (3).

The majority of per-oral CR dosage forms fall in the category of matrix, reservoir or osmotic systems. Drug release from matrix and reservoir systems is affected by $\mathrm{pH}$, hydrodynamic conditions and the presence of food in the gastro-intestinal tract (2). Osmotic systems utilize the principles of osmotic pressure for controlled delivery of drugs (4). Drug release from these systems is to a large extent independent of $\mathrm{pH}$ and other physiological parameters (5). The development of oral osmotic systems has a large market potential, as evident from the marketed products and number of patents granted in the last few years $(6,7)$.

Tramadol hydrochloride (TRH), a centrally acting opioid analgesic, is used in severe acute or chronic pains (8). It offers several therapeutic advantages over other analgesics, such as good oral bioavailability and long elimination half-life $(5-7 \mathrm{~h})$. Despite the long elimination half-life, TRH is prescribed 3-4 times a day (9). Frequent dosing schedule often leads to decreased patient compliance, increased incidence of side effects and tolerance development, especially, in long-term use (10) in conditions like arthritis, osteoarthritis, arthralgia, postoperative surgical pains, etc. It seems that there is a strong clinical need and market potential for a delivery system that can deliver TRH in a controlled manner.

The present study was thus aimed at the development of extended release formulation of TRH based on osmotic technology.

\section{EXPERIMENTAL}

\section{Materials}

Tramadol hydrochloride (98.7 \% purity) was obtained from Win Medicare Ltd, India. Polyethylene oxide $\left(M_{\mathrm{r}} 300000\right)$ was a received from Torrent Research Centre, India. The following chemicals and excipients were purchased from commercial sources and were used as such: cellulose acetate (39.8 \% acetylation), polyvinyl pyrrolidone (PVP K-30), microcrystalline cellulose (MCC pH 102), magnesium stearate, talc, sodium chloride (all from CDH, India), acetone, methanol (HPLC grade), acetonitrile (HPLC grade), triethanolamine, fructose, mannitol (all from Qualigens Fine Chemicals, India), disodium hydrogen orthophosphate, orthophosphoric acid (all from S.D. Fine Chemicals, India). TRD CONTIN $^{\circledR}$ (Modi-Mundi Pharmaceuticals, India, $100 \mathrm{mg}$ sustained release tablet) and Tramazac $^{\circledR}$ (Zydus Cadila Pharmaceuticals, India, $50 \mathrm{mg}$ conventional tablet) were purchased from a retail pharmacy.

\section{Formulation development}

Before initiating formulation development, compatibility of TRH with different excipients was tested using the techniques of DSC (Du-Pont, Model 9900, USA) and FT-IR (Shimadzu, Model 8400S, Japan). Excipients used in the final formulation were found to be compatible with TRH. 
P. Kumar et al.: Development and biopharmaceutical evaluation of extended release formulation of tramadol hydrochloride based on osmotic technology, Acta Pharm. 59 (2009) 15-30.

Core tablets of TRH were prepared by direct compression and batch size was 100 tablets. Formulas of different core formulations of TRH are listed in Table I. TRH was mixed with polyethylene oxide (PEO) for $10 \mathrm{~min}$. After passing this mixture through a sieve $600 \mu \mathrm{m}$, osmotic agents (fructose or mannitol), MCC and PVP were added in geometric dilution and mixing continued for an additional $10 \mathrm{~min}$. To this mix, talc and magnesium stearate passed through $250 \mu \mathrm{m}$ sieve, were added and mixing continued for an additional $10 \mathrm{~min}$. The blend was then compressed into tablets of average mass of 300-320 mg using a single station tablet punching machine (Manesty E-2, UK) fitted with $8 \mathrm{~mm}$ round standard concave punches. The punched tablets were of $6.0 \pm 0.38 \mathrm{~kg} \mathrm{~cm}^{-2}$ hardness on the Monsanto hardness tester (Campbell Electronics, India).

TRH core tablets were coated in a conventional laboratory coating pan (Scientific Instrument, India) fitted with three baffles placed at an angle of $120^{\circ}$ having the outer diameter of $10 \mathrm{~cm}$ (11). The composition of solutions used for coating TRH tablets is given in Table II. The coating process was done on a batch of 100 tablets; pan speed was maintained at $20 \mathrm{rpm}$ and hot air inlet temperature was kept at $38-42{ }^{\circ} \mathrm{C}$ (11). The manual coating procedure based on intermittent spraying and coating was used at a spray rate of 4-5 mL min ${ }^{-1}$. Coat mass and thickness were controlled by the volume of coating so-

Table I. Formula for different batches of core formulation

\begin{tabular}{lccccc}
\hline \multirow{2}{*}{$\begin{array}{c}\text { Ingredients } \\
\text { (mg per tablet })\end{array}$} & I & II & III & IV & Va \\
\cline { 2 - 6 } & 100 & 100 & 100 & 100 & 100 \\
\hline Tramadol hydrochloride & - & 136 & 136 & 136 & 136 \\
Mannitol & 136 & - & - & - & - \\
Fructose & - & - & 30 & 50 & 70 \\
PEO & 50 & 50 & 20 & - & - \\
MCC & 10 & 10 & 10 & 10 & 10 \\
PVP & 2 & 2 & 2 & 2 & 2 \\
Talc & 2 & 2 & 2 & 2 & 2 \\
Magnesium stearate & & &
\end{tabular}

PEO - polyethylene oxide, MCC ( $\mathrm{pH}$ 102) - microcrystalline cellulose, PVP K-30 - polyvinylpyrrolidone

a Batch with average mass of $320 \mathrm{mg}$. Other batches are of average mass $300 \mathrm{mg}$.

Table II. Composition of coating solutions

\begin{tabular}{lccr}
\hline \multirow{2}{*}{ Ingredients } & \multicolumn{3}{c}{ Coat code } \\
\cline { 2 - 4 } & $\mathrm{A}$ & $\mathrm{B}$ & \multicolumn{1}{c}{$\mathrm{C}$} \\
\hline Cellulose acetate $(\mathrm{mg})$ & 4000 & 4000 & 4000 \\
PEG-400 $(\mathrm{mg})$ & - & 400 & 800 \\
Methanol $(\mathrm{mL})$ & 10 & 10 & 10 \\
Acetone $(\mathrm{mL})$ & 90 & 90 & 90 \\
\hline
\end{tabular}


P. Kumar et al.: Development and biopharmaceutical evaluation of extended release formulation of tramadol hydrochloride based on osmotic technology, Acta Pharm. 59 (2009) 15-30.

lution consumed in the coating process (11). Coating was continued until the desired coat thickness $(150 \mu \mathrm{m})$ was obtained on the core tablets. An appropriate size orifice $(0.5 \mathrm{~mm})$ was made on one face of all the coated tablets using a microdrill (Kamlesh Engineers, India) (12). In all the cases, coated tablets were dried at $50{ }^{\circ} \mathrm{C}$ for $10 \mathrm{~h}$ before further evaluation.

\section{Surface morphology study}

To investigate the changes in the membrane structure due to the presence of plasticizer (PEG-400), the surface of coated tablets (both before and after dissolution studies) was studied using SEM (JEOL, JSM-6100, Japan). The samples were placed on a spherical brass stub (12 $\mathrm{mm}$ diameter) with a double backed adhesive tape. The mounted samples were sputter coated for 5 to 10 min with gold using a fine coat ion sputter (Jeol, JFC-1100, Japan) and examined under SEM (Jeol, JSM-6100, Japan).

\section{Evaluation of developed formulation}

Bulk and tap density of the powdered blend was determined using the USP method II (13) and the compressibility index and Hausner ratio were calculated.

The core and coated tablets were evaluated for mass variation. Thickness and diameter of the core and coated tablets were measured using screw gauze (Ultra Science Aid, India). Hardness of randomly selected tablets was tested using a hardness tester (Monsanto hardness tester). Friability of 20 core tablets was carried out on a Cintex friability test apparatus (Cintex, India).

The developed formulation $(n=3)$ of TRH was subjected to release studies using a USP dissolution apparatus type II (Campbell Electronics, India) at $50 \mathrm{rpm}$ (13). Dissolution medium used was simulated intestinal fluid (SIF) ( $\mathrm{pH} 6.8,900 \mathrm{~mL}$ ) maintained at $37 \pm 0.5^{\circ} \mathrm{C}$, which was found to provide sink conditions (solubility of TRH was determined to be $\left.>0.5 \mathrm{~g} \mathrm{~mL}^{-1}\right)(14)$. The samples were withdrawn $(5 \mathrm{~mL})$ at different time intervals and replaced with equivalent amounts of fresh medium. Dissolution samples, after filtration through a $0.45-\mu \mathrm{m}$ nylon membrane filter, were analyzed using an already reported validated HPLC method at $271 \mathrm{~nm}(15,16)$. After analyzing the drug content in the dissolution samples, corrections were made for volume replacement and the graph of cumulative percent of drug release vs. time was plotted.

Release profiles of various batches were compared using a model independent pairwise approach, which includes calculation of the 'difference factor' $f 1$ and 'similarity factor' $f 2$. The two release profiles were considered to be similar if $f 1$ value was lower than 15 (between 0 and 15) and $f 2$ value was more than 50 (between 50 and 100). Release profiles were also compared using the mean dissolution time (MDT), which was calculated using the following equation (17):

$$
M D T=\frac{\sum_{j=1}^{n} \hat{t} \Delta M j}{\sum_{j=1}^{n} \Delta M j}
$$


P. Kumar et al.: Development and biopharmaceutical evaluation of extended release formulation of tramadol hydrochloride based on osmotic technology, Acta Pharm. 59 (2009) 15-30.

where $j$ is the sample number, $n$ is the number of dissolution sample times, $\hat{t} j$ is the time at mid-point between $t j$ and $t(j-1)$, and $\Delta M j$ is the additional amount of drug dissolved between $t j$ and $t(j-1)$. One-way analysis of variance test (ANOVA) was performed to check whether there was a significant difference between different formulations.

In this study, the mean dissolution time for $50 \%$ drug release $\left(M D T_{50}\right)$ was used for comparison of release profiles from different batches.

For content uniformity testing, accurately weighed tablets $(n=20)$ were dissolved in $500 \mathrm{~mL}$ of distilled water (18). The samples were sonicated for $30 \mathrm{~min}$ and filtered through a $0.45-\mu \mathrm{m}$ nylon membrane filter. The filtered samples, after appropriate dilution with the mobile phase, were analyzed at $271 \mathrm{~nm}$ using HPLC (Cecil HPLC system, UK).

\section{HPLC analysis}

For in vitro and in vivo analysis of drug samples, the Cecil HPLC system equipped with an adept series dual piston pump CE-4100, manual injector Caplugs RC-11 and adept series variable wavelength UV/Vis detector CE-4201 was used. Reverse phase HPLC method was carried out using a phenomenex C-18 column $(4.6 \times 250 \mathrm{~mm}, 5 \mathrm{~mm}$ particle size) at $25^{\circ} \mathrm{C}$. The optimized mobile phase composition was phosphate buffer (0.01 mol L-1)/acetonitrile/triethanolamine (75:25:0.1) at a flow rate of $1 \mathrm{~mL} \mathrm{~min}^{-1}$. Injected volume was $20 \mathrm{~mL}$ and detection was performed at $271 \mathrm{~nm}(15,16)$.

\section{In vivo studies}

In vivo studies were performed following the standard protocols on six healthy human volunteers of either sex weighing $55-75 \mathrm{~kg}$ and 24-29 years old in a crossover design with a wash-out period of one week. Volunteers agreed in writing to participate in the study after being informed about the experimental protocol. All the subjects were in good health according to their medical history and complete medical examination. Heparinized blood samples were taken at the following times: 0.5, 1, 2, 4, 6, 8, 10, 12 and $24 \mathrm{~h}$ post administration and stored at $-4{ }^{\circ} \mathrm{C}$ till further used.

The experimental protocol was approved by the human ethical committee, Banaras Hindu University, India.

Plasma samples were prepared by liquid-liquid extraction. Plasma $(250 \mu \mathrm{L})$ was mixed with $100 \mu \mathrm{L} \mathrm{NaOH}\left(1 \mathrm{~mol} \mathrm{~L}^{-1}\right)$ in a $4-\mathrm{mL}$ test tube and then extracted with $1.25 \mathrm{~mL}$ of ethyl acetate. After vertical agitation $(10 \mathrm{~min})$ and centrifugation $(10,000 \mathrm{rpm}, 10 \mathrm{~min})$, the upper organic layer was transferred into a conical glass tube. Extraction was repeated using another $1.25 \mathrm{~mL}$ of ethyl acetate. The organic phase was then evaporated under a gentle stream of air and reconstituted in $250 \mu \mathrm{L}$ of a mobile phase $(15,16)$.

\section{In vitro-in vivo correlation}

In vitro-in vivo correlation of the optimized batch was investigated by plotting the percent dissolved $\left(F_{\mathrm{r}}\right)$ vs. percent absorbed $\left(F_{\mathrm{a}}\right)$ drug. Percent dissolved values were taken from in vitro release data and percent absorbed was determined by the Wagner-Nelson method using the following equation (19): 
P. Kumar et al.: Development and biopharmaceutical evaluation of extended release formulation of tramadol hydrochloride based on osmotic technology, Acta Pharm. 59 (2009) 15-30.

$$
F_{a}=\left[\left(C_{t}+k_{e} A U C_{0-t}\right) / k_{e} A U C_{0-\infty}\right] \times 100
$$

where $F_{a}$ is the fraction of drug absorbed, $C_{t}$ is the drug plasma concentration at time $t$, $k_{e}$ is the overall elimination rate constant, $A U C_{0-t}$, and $A U C_{0-\infty}$ are areas under the curve between time zero and time $t$ and between time zero and infinity, respectively.

\section{RESULTS AND DISCUSSION}

\section{Desired drug release profile}

Using the different pharmacokinetic parameters of TRH (Table III), the dose needed to provide controlled delivery of TRH can be calculated by the following equation (20):

$$
D_{0}=C_{p} T C l_{T}
$$

where $D_{0}$ is the dose, $C_{p}$ is the therapeutic drug plasma level, $C l_{T}$ is total clearance and $T$ is the dosing interval. Therapeutic range for TRH is reported to be between $0.1-0.3 \mu \mathrm{g}$ $\mathrm{mL}^{-1}(21)$ and the desired steady state concentration of TRH for a $100 \mathrm{mg}$ (four times a day) dose is $0.225 \mu \mathrm{g} \mathrm{mL}^{-1}$. Taking the steady state concentration as the desired therapeutic plasma level and the dosing interval of $12 \mathrm{~h}$, the following values were proposed: (i) sustaining dose $100 \mathrm{mg}$, (ii) zero-order release rate $8.1 \mathrm{mg} \mathrm{h}^{-1}$, (iii) dosing interval $12 \mathrm{~h}$. By plotting the cumulative zero-order release $(\%)(y)$ vs. time $(\mathrm{x})$, the desired release profile was generated and used as the target release profile for developed formulations $(\mathrm{y}=8.1 \mathrm{x})$.

\section{Effect of formulation variables}

In the initial trial, TRH core tablets (batch I) were coated with the coating composition code B (formulation code batch IB). Release studies showed that more than $85 \%$ of the drug was delivered within $5 \mathrm{~h}$ (Fig. 1). This may be due to the high solubility of TRH or high osmotic pressure generation within the core compartment. To reduce the osmotic

Table III. Various pharmacokinetic parameters of tramadol hydrochloride

\begin{tabular}{llc}
\hline \multicolumn{1}{c}{ Pharmacokinetic parameter } & \multicolumn{1}{c}{ Value } & References \\
\hline Bioavailability $(f)$ & $74 \%$ & 8,9 \\
Elimination half-life $\left(t_{1 / 2}\right)$ & $6.3 \mathrm{~h}$ & 9,10 \\
Terminal disposition rate constant $\left(K_{\mathrm{el}}\right)$ & $0.11 \mathrm{~h}^{-1}$ & $8-10$ \\
Apparent volume of distribution $\left(V_{\mathrm{d}}\right)$ & $2.71 \mathrm{~kg}^{-1}$ & 8,9 \\
Maximum effective conc. $\left(c_{\max }\right)$ & $0.3 \mu \mathrm{g} \mathrm{mL}^{-1}$ & 22 \\
Minimum effective conc. $\left(c_{\min }\right)$ & $0.1 \mu \mathrm{g} \mathrm{mL}^{-1}$ & 22 \\
Total clearance $\left(C l_{\mathrm{T}}\right)$ & $8.5 \mathrm{~mL} \mathrm{~min}^{-1} \mathrm{~kg}^{-1}$ & $8-10$ \\
\hline
\end{tabular}


Fig. 1. Effect of PEO, plasticizer level and semipermeable membrane coat thickness on TRH release release from the developed formulations. Points represents mean $\pm \mathrm{SD}(n=3)$.

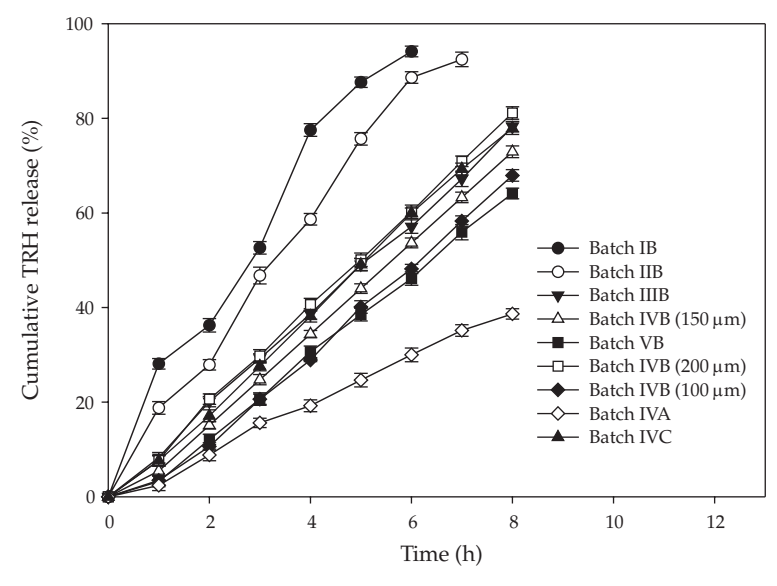

pressure in the core compartment, mannitol (38 atm, saturated solution) (7) was used in place of fructose (335 atm, saturated solution) (7) within the core (batch IIB). This approach was unsuccessful as more than $75 \%$ drug was released within $5 \mathrm{~h}$ (Fig. 1).

Osmotic pumps per se are suitable for the delivery of drugs having intermediate water solubility (2). It has been reported that in case of water-insoluble drugs, reasonable release rates may not be obtained using an elementary osmotic pump or controlled-porosity osmotic pump (5). This is because the kinetics of osmotic drug release is directly related to drug solubility within the core. Assuming a tablet core of pure drug, the fraction of drug released with zero-order kinetics is given by:

$$
F(z)=1-\frac{S}{\rho}
$$

where $F(\mathrm{z})$ is the fraction released by zero-order kinetics, $S$ is the drug solubility $\left(\mathrm{g} \mathrm{mL}^{-1}\right)$, and $\rho$ is the density $\left(\mathrm{g} \mathrm{mL}^{-1}\right)$ of the core tablet. Drugs with a solubility of $\leq 0.05 \mathrm{~g} \mathrm{~mL}^{-1}$ would be released with $\geq 95 \%$ zero-order kinetics according to Eq. (4). However, the zero-order release rate would be slow according to Eq. (5), due to the small osmotic pressure gradient:

$$
\frac{d m}{d t}=\frac{A}{h} \sigma L_{p}(\Delta \pi-p) C
$$

$E q$. (5) describes drug release from osmotic pumps, where $d m / d t$ is the drug delivery rate, $A$ and $h$ are the membrane area and thickness, respectively, $c$ is the concentration (or the solubility, when excess of drug is present in the core) of the drug in the dispensed fluid, $\Delta \pi$ is the osmotic pressure difference across the film, $\sigma L_{p}$ is the hydraulic permeability of the membrane and $p$ is the hydrostatic pressure within the core compartment.

According to Eq. (4), highly water-soluble drugs would demonstrate a high release rate, which would be zero-order for a small percentage of the initial drug load. Thus, the 
P. Kumar et al.: Development and biopharmaceutical evaluation of extended release formulation of tramadol hydrochloride based on osmotic technology, Acta Pharm. 59 (2009) 15-30.

intrinsic water solubility of many drugs might preclude them from incorporation into an osmotic pump. However, it is possible to modulate the solubility of drugs within the core, and thus extend this technology for delivery of drugs that may otherwise be poor candidates for osmotic delivery.

TRH is a basic drug with very high water solubility; $p K_{a}$ value of TRH is 9.41 , hence solubility is also $\mathrm{pH}$ independent at physiological $\mathrm{pH}$ (11). In order to get the desired release from the developed systems, PEO was added to the core formulation. After coming in contact with the surrounding fluid, swellable polymer (PEO) causes significant swelling, which creates significant internal pressure within the osmotic system leading to reduced imbibition. Also, the PEO within the core may restrict or delay the contact of solvent molecules with the drug and osmotic agent molecules, which may result in decreased osmotic pressure generation within the device and thus control the release of the drug from EOP $(22,23)$. Three batches were prepared, in which the PEO concentration was varied. Batches III, IV and V were coated with the coating composition code B and formulations coded as batch IIIB, IVB, VB containing $10 \%, 16.6 \%$, and $23.3 \%(\mathrm{~m} / \mathrm{m})$ of PEO respectively. In vitro release profiles of three batches (IIIB, IVB, VB) compared to batch IIB (without PEO) are compared in Fig. 1. It is clearly evident that the concentration of PEO has an inverse effect on drug release. With an increase in the PEO concentration within the core there was a decrease in drug release and an increase in swelling of the formulations due to higher internal pressure generated by PEO. The differences in $M D T_{50}$ between the above formulations $(1.44,2.56,3.01,3.57 \mathrm{~h}$ for batch IIB, IIIB, IVB and VB, resp.) were found to be statistically significant $(p<0.05)$.

To study the effect of coat thickness of the semipermeable membrane (SPM) on drug release, core tablets of TRH (batch IV) were coated with the coating composition code B so as to give coat thickness of 100, 150 and $200 \mu \mathrm{m}$. Release profiles of TRH from these formulations are shown in Fig. 1. It is clearly evident that drug release decreases with the increase in coat thickness of SPM. The differences in $M D T_{50}$ between the above formulations $(2.56,3.19,4.12 \mathrm{~h}$ for $100-150$ - and $200-\mu \mathrm{m}$ coat thrickeness) were found to be statistically significant $(p<0.05)$.

To study the effect of the level of plasticizer (PEG-400), core formulation (batch IV) of TRH was coated with coating composition code A and C with no PEG-400 and containing $20 \%(\mathrm{~m} / \mathrm{m})$ PEG-400 (of cellulose acetate mass), respectively (batches IVA and IVC). Release profiles of these formulations in comparison with batch IVB [containing $10 \%$ $(\mathrm{m} / \mathrm{m})$ PEG-400 of cellulose acetate mass] are shown in Fig. 1. It is clearly evident that the level of plasticizer, PEG-400, has a direct effect on drug release. As the level of PEG-400 increases, the membrane becomes more porous due to rapid dissolution of water soluble PEG-400 in dissolution medium, resulting in higher drug release (11).

In vitro drug release profiles of the promising batches IIIB, IVB and VB were compared with commercial immediate release Tramazac ${ }^{\circledR}-50 \mathrm{mg}$ (M1) and sustained release TRD-CONTIN $^{\circledR}-100 \mathrm{mg}$ (M2) formulations of TRH and also with the theoretically desired release profile (Fig. 2). It is clearly evident that the developed formulations provided more controlled and prolonged drug release compared to commercial formulations of TRH. Drug release from batch IVB was found to be closest to the desired release profile. The $f 1$ and $f 2$ values for batch IVB were 5.71 and 82.31 , respectively, taking the desired release profile as reference, indicating no significant difference between batch IVB 
Fig. 2. Comparison of promising formulations with commercial formulations and the theoretically desired release profile. Points represent mean \pm SD $(n=3)$.

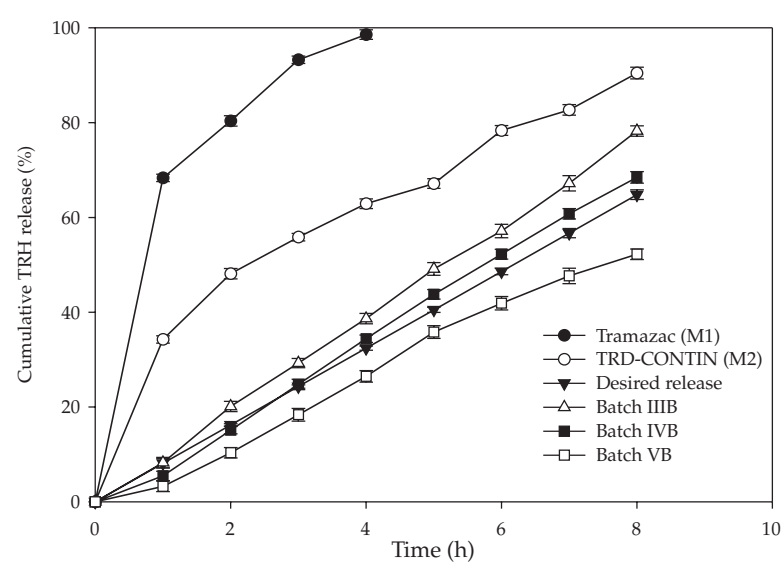

and the theoretically desired release profile. Formulation IVB was therefore selected as the optimized formulation and was further evaluated.

\section{Evaluation of the optimized formulation}

The optimized batch IVB was evaluated for various pharmacopoeial and non-pharmacopoeial tests, results of which are listed in Table IV. The powder blend was free flowing, as demonstrated by the values of the compressibility index (less than 15) and Hausner ratio (less than 1.25). Exhausted shells, after dissolution, were visually observed for any imperfection or cracks in the coating. There were no visible cracks in the coating and it was found to be intact in all batches after $8 \mathrm{~h}$ of dissolution studies.

To study the effect of $\mathrm{pH}$ and to assure a reliable performance, release studies of the optimized formulation were conducted according to the $\mathrm{pH}$ change method (initial $2 \mathrm{~h}$

Fig. 3. Effect of $\mathrm{pH}$, agitation intensity and osmotic pressure of dissolutiom medium on TRH release from developed formulations. Points represent mean \pm SD $(n=3)$.

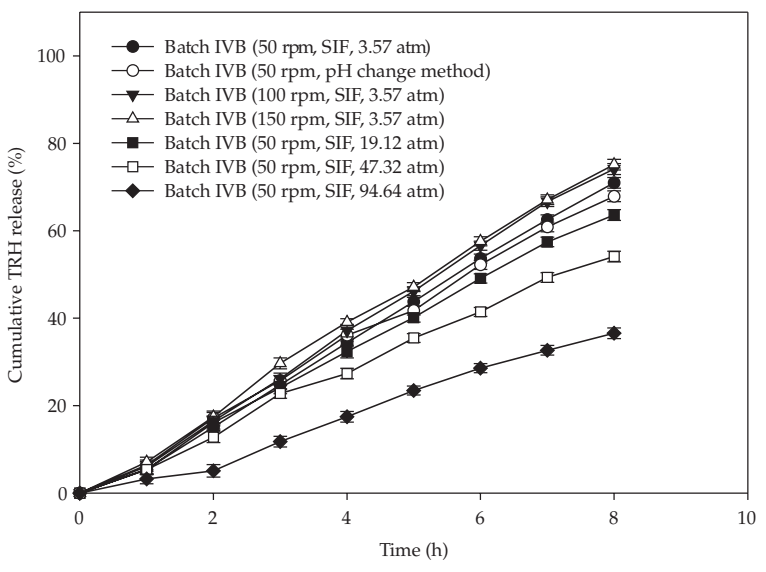


P. Kumar et al.: Development and biopharmaceutical evaluation of extended release formulation of tramadol hydrochloride based on osmotic technology, Acta Pharm. 59 (2009) 15-30.

Table IV. Properties of the powdered blend, core tablets, and final coated tablets of the optimized formulation (batch IVB)

\begin{tabular}{|c|c|}
\hline Parameter & Mean value $( \pm S D)$ \\
\hline Bulk density $\left(\mathrm{mg} \mathrm{mL}^{-1}\right)^{\mathrm{a}}$ & 415 \\
\hline Tap density $\left(\mathrm{mg} \mathrm{mL}^{-1}\right)^{\mathrm{a}}$ & 464 \\
\hline Compressibility index $(\%)^{\mathrm{a}}$ & 8.69 \\
\hline Hausner ratio ${ }^{\mathrm{a}}$ & 1.08 \\
\hline Core tablet mass (mg, $n=10)$ & $300.12( \pm 5.21)$ \\
\hline Coated tablet mass $(\mathrm{mg}, n=10)$ & $318.21( \pm 4.62)$ \\
\hline Core tablet thickness (mm, $n=10$ ) & $4.12( \pm 0.02)$ \\
\hline Coated tablet thickness $(\mathrm{mm}, n=10)$ & $4.48( \pm 0.02)$ \\
\hline Core tablet diameter $(\mathrm{mm}, n=10)$ & $8.11( \pm 0.11)$ \\
\hline Coated tablet diameter $(\mathrm{mm}, n=10)$ & $8.32( \pm 0.02)$ \\
\hline Core tablet hardness $\left(\mathrm{kg} \mathrm{cm}^{-2}, n=10\right)$ & $6.12( \pm 1.12)$ \\
\hline Coated tablet hardness $\left(\mathrm{kg} \mathrm{cm}^{-2}, n=10\right)$ & $10.24( \pm 1.48)$ \\
\hline Friability $(\%, n=20)^{\mathrm{b}}$ & 0.096 \\
\hline Content uniformity $(\%, n=20)^{\mathrm{c}}$ & $102.46( \pm 2.24)$ \\
\hline
\end{tabular}

a Property of powdered blend; ${ }^{b}$ property of core tablet; ${ }^{c}$ Property of final coated tablet.

in $\mathrm{pH} 1.2$, next $2 \mathrm{~h}$ in $\mathrm{pH} 4.5,2 \mathrm{~h}$ in $\mathrm{pH} 6.8$ and finally $2 \mathrm{~h}$ in $\mathrm{pH} 7.4$ ) and compared to release data in SIF. There was a not a significant difference between different $\mathrm{pHs}$ of release medium on TRH release compared to in vitro data in SIF (Fig. 3 ). The $f 1$ and $f 2$ values of batch IVB were found to be 2.65 and 91.85 respectively, taking the release profile in SIF as reference.

To study the effect of hydrodynamic conditions on TRH release, a release study of batch IVB was carried out at three different rotational paddle speeds (50, 100, $150 \mathrm{rpm}$ ). There was an insignificant effect of rotational speed on TRH release from developed formulations when all the three release profiles were compared (Fig. 3 ). The $f 1$ and $f 2$ values were found to be 4.22 and 85.09 (between 50 and $100 \mathrm{rpm}$ ), 3.71 and 85.78 (between 100 and $150 \mathrm{rpm}$ ), and 7.77 and 73.33 (between 50 and $150 \mathrm{rpm}$ ), respectively.

To study the effect of osmotic pressure, release studies of the optimized formulation were conducted in media of different osmotic pressure $(19.12,47.32,94.64 \mathrm{~atm})$. The results showed that the drug release was highly dependent on the osmotic pressure of the release media. TRH release from the formulations decreased as the osmotic pressure of the media increased (Fig. 3). Thus it was concluded that osmotic pumping is the major mechanism governing drug release from developed formulations.

Before dissolution studies, all membranes (Figs. 4a,b, and c) looked similar and no porous membrane structure was observed with different levels of plasticizer (PEG-400). Fig. $4 \mathrm{~b}$ shows the SEM micrograph of a membrane with no PEG-400 (batch IVA). It shows a surface morphology similar to that of Fig. 4a, suggesting that there is no evidence of development of pores in the membrane after the dissolution study. On the other hand, 
P. Kumar et al: Development and biopharmaceutical evaluation of extended release formulation of tramadol hydrochloride based on osmotic technology, Acta Pharm. 59 (2009) 15-30.

there was formation of pores in membranes of batches IVB and IVC (Figs. 4d,f) after dissolution studies. This might be due to the rapid dissolution of the water soluble plasticizer (PEG-400) in dissolution medium. When comparison was made of the membranes containing different levels of plasticizer (Figs. $4 \mathrm{~b}, \mathrm{~d}, \mathrm{f}$ ), it was found that the membrane that contained a higher level of plasticizer became more porous after the dissolution studies.

a)

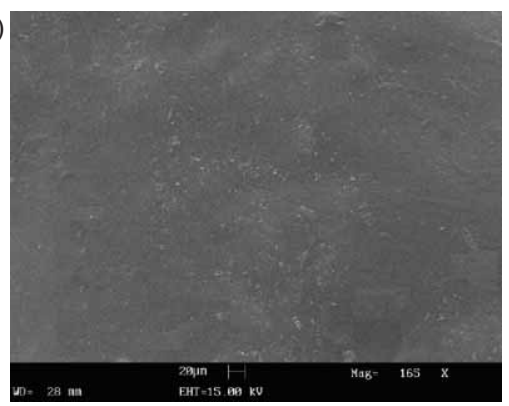

C)

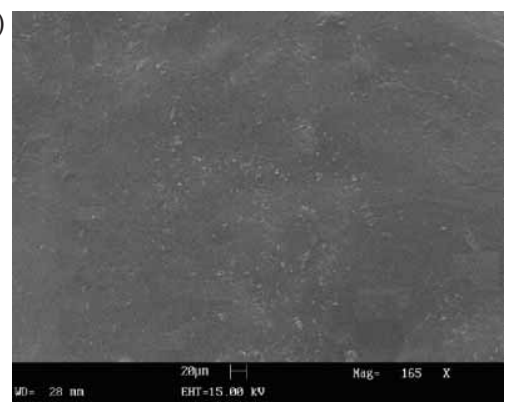

e)

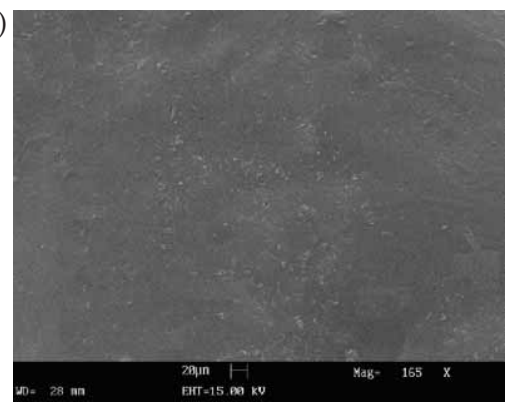

b)

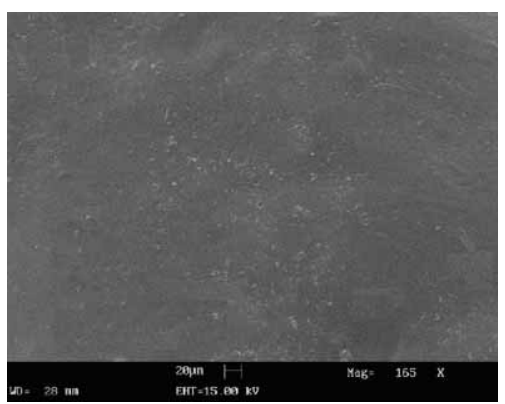

d)

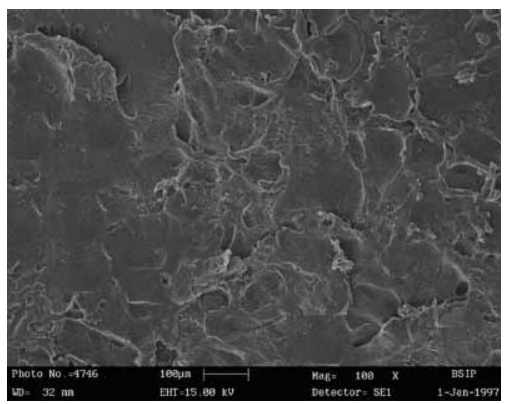

f)

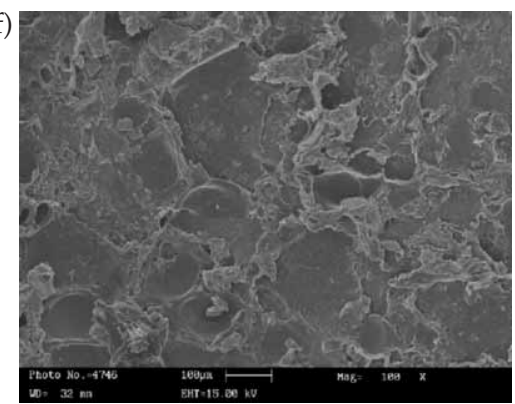

Fig. 4. SEM micrograph showing the membrane structure of formulation batches IVA, IVB and IVC (150 $\mu \mathrm{m}$ coat thickness). Panels a, c, and e represent SEM micrographs before the dissolution study of batches IVA, IVB and IVC, respectively, whereas panels $b, d$, and $f$ represent SEM micrographs after the dissolution study of batches IVA, IVB and IVC, respectively. 
P. Kumar et al.: Development and biopharmaceutical evaluation of extended release formulation of tramadol hydrochloride based on osmotic technology, Acta Pharm. 59 (2009) 15-30.

\section{Kinetics and mechanism of drug release}

Dissolution data of the optimized formulation (batch IVB) was fitted to various mathematical models (zero-order, first-order and Higuchi) in order to describe the kinetics of drug release (17). Smallest value of the sum of squared residuals (SSR), Akaike information criterion (AIC) and the best goodness-of-fit test $\left(R^{2}\right)$ were taken as criteria for selecting the most appropriate model. Drug release from optimized formulations fitted well into zero-order kinetics (Table V), confirming that the release from formulations is close to the desired release profile and drug load dependent.

\section{Reproducibility and accelerated stability study}

Reproducibility of the manufacturing procedure was confirmed by preparing three repeated batches of the final optimized formulation on three different occasions. Release studies were conducted in SIF and similar release profiles were obtained from all repeated batches, demonstrating that the manufacturing procedure is reproducible. The $f 1$ and $f 2$ values were found to be 4.11 and 85.07 (between repeat batches 1 and 2), 3.26 and 89.46 (between repeat batches 1 and 3), and 5.23 and 81.68 (between repeat batches 2 and 3), respectively.

Optimized TRH formulations were packed in strips of $0.04 \mathrm{~mm}$ thick aluminum foil laminated with polyvinyl chloride (PVC). Packed formulations were stored in stability chambers (Narang Scientific Work, India) maintained at $40{ }^{\circ} \mathrm{C}$ and $75 \%$ relative humidity for 6 months (24). Stored formulations of optimized batch with $150-\mu \mathrm{m}$ coat thickeness were found to be stable in terms of physical properties, hardness, in vitro release characteristics and dissolution stability (Table VI) even after storage for 6 months. Despite statistically significant variability in the drug content, the tested formulation adhered to $\mathrm{ICH}(24)$ criterion of $\leq 5 \%$ drug content change from its initial value.

\section{In vivo study and in vitro-in vivo correlation}

The plasma TRH concentration vs. time profile (Fig. 5) obtained from the in vivo study clearly shows that the developed formulations (batch IIIB and batch IVB) maintained a constant therapeutic TRH concentration within the plasma even up to $24 \mathrm{~h}$, as compared

Table V. Fitting drug release of the optimized formulation (batch IVB) according to various mathematical models

\begin{tabular}{lcccccc}
\hline \multirow{2}{*}{ Model } & \multicolumn{7}{c}{ Parameters used } \\
\cline { 2 - 7 } & $R$ & Intercept $(\%)$ & Slope $\left(\% \mathrm{~h}^{-1}\right)$ & $k^{\mathrm{a}}$ & SSR & AIC \\
\hline Zero-order & 0.9996 & -2.9071 & 9.423 & 8.371 & 25.8 & 15.36 \\
First-order & 0.9370 & 1.9157 & 0.332 & 0.3326 & 216.12 & 32.36 \\
Higuchi model & 0.9903 & -36.8103 & 37.359 & 37.3597 & 128.42 & 26.18 \\
\hline
\end{tabular}

$R$ - correlation coefficient, SSR - sum of squares of residuals, AIC - Akaike information criteria, $k$ - release rate constant for respective models, a $k_{0}$ in $\mathrm{mg} \mathrm{h}^{-1}, k_{1}$ in $\mathrm{h}^{-1}$ and $k_{\mathrm{H}}$ in $\% \mathrm{~h}^{-1 / 2}$ for zero-order, first order and Higuchi rate equations models respectively. 
P. Kumar et al.: Development and biopharmaceutical evaluation of extended release formulation of tramadol hydrochloride based on osmotic technology, Acta Pharm. 59 (2009) 15-30.

Table VI. Batch IVB stability ${ }^{a}$

\begin{tabular}{lcccc}
\hline \multicolumn{1}{c}{ Parameter } & Initial & 2 month & 4 month & 6 month \\
\hline Drug content $(\% \pm \mathrm{SD}, n=20)$ & $102.60 \pm 1.44$ & $99.68 \pm 1.87^{\mathrm{b}}$ & $98.14 \pm 1.67^{\mathrm{b}}$ & $104.60 \pm 1.61^{\mathrm{b}}$ \\
Hardness (mean $\pm \mathrm{SD}, n=10)$ & $7.33 \pm 1.98$ & $7.98 \pm 1.68$ & $7.33 \pm 1.48$ & $8.13 \pm 1.52$ \\
$f 1$ & - & 2.32 & 4.52 & 5.12 \\
$f 2$ & - & 92.62 & 84.62 & 82.24 \\
$\mathrm{MDT}_{50}$ & 3.004 & 3.271 & 3.151 & 3.208 \\
\hline
\end{tabular}

a 6 months storage at $40{ }^{\circ} \mathrm{C}$ and $75 \% \mathrm{RH}$

b Significant difference $(p<0.05)$ vs. initial value.

to commercial formulations M1 and M2, which showed a rapid decline in drug concentration with time. The developed formulations showed lower $c_{\max }$ (but within therapeutic range) and higher $t_{\max }$ values than commercial tablets (Table VII). Lower $c_{\max }$ for batches IIIB and IVB indicate avoidance of the risk of exceeding the maximum safe concentration. Higher $t_{\max }$ for batches IIIB and IVB is indicative of drug release occurring at a slower rate than from commercial tablets. Significantly higher value of $A U C_{0-24}$, relative bioavailability and mean residence time $(M R T)$ for batch IVB compared to M1 and M2 (Table VII) further indicate the superiority of the developed formulation over commercial immediate release (M1) and sustained release (M2) tablets of TRH, in terms of providing controlled drug release for a longer time and improved bioavailability.

An in vitro-in vivo correlation of batch IVB was carried out using the Wagner-Nelson method (20). Percent drug dissolved (x) when plotted against percent drug absorbed $(\mathrm{y})$ gives a good linear regression $\mathrm{y}=1.49 \mathrm{x}+7.838$ (Table VIII). The correlation coefficient $R$ of 0.9750 indicates a good correlation up to almost $54 \%$ in vitro drug release.

Fig. 5. Plasma profiles of TRH following oral administration of developed formulations compared to commercial formulations to healthy human subjects. Points represent mean $\pm \operatorname{SD}(n=6)$.

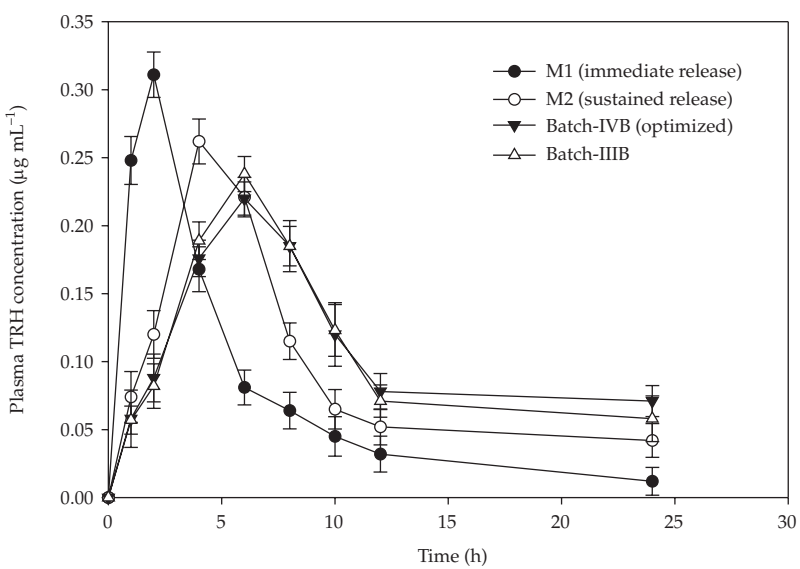


P. Kumar et al.: Development and biopharmaceutical evaluation of extended release formulation of tramadol hydrochloride based on osmotic technology, Acta Pharm. 59 (2009) 15-30.

Table VII. Bioavailability and pharmacokinetic parameters following oral administration of developed formulations (batches IIIB and IVB) and marketed formulations (M1 and M2) of TRH

\begin{tabular}{ccccccc}
\hline Batch & $\left.c_{\max }(\mu \mathrm{g} \mathrm{mL})^{-1}\right)^{\mathrm{a}}$ & $t_{\max }(\mathrm{h})^{\mathrm{a}}$ & $A U_{0-24}\left(\mu \mathrm{g} \mathrm{h} \mathrm{mL} \mathrm{mL}^{-1}\right)^{\mathrm{a}}$ & $\mathrm{RB}_{1}(\%)$ & $\mathrm{RB}_{2}(\%)$ & $\mathrm{MRT}(\mathrm{h})$ \\
\hline IIIB & $0.238 \pm 0.024$ & $6.8 \pm 0.5$ & $2.457 \pm 0.320$ & 123.77 & 110.87 & 13.7 \\
IVB & $0.220 \pm 0.064$ & $7.5 \pm 0.4$ & $2.632 \pm 0.280$ & 132.59 & 118.77 & 14.2 \\
M2 & $0.270 \pm 0.063$ & $4.3 \pm 0.4$ & $2.216 \pm 0.230$ & 111.63 & 100 & 9.1 \\
M1 & $0.325 \pm 0.075$ & $1.7 \pm 0.5$ & $1.985 \pm 0.310$ & 100.00 & 89.58 & 4.2 \\
\hline
\end{tabular}

AUC - area under curve, $\mathrm{RB}_{1}$ - relative bioavailability with reference to $\mathrm{M} 1$ (immediate release formulation), $\mathrm{RB}_{2}$ - relative bioavailability with reference to $\mathrm{M} 2$ (sustained release formulation)

a Mean $\pm \operatorname{SD}(n=6)$.

Table VIII. Correlation between in vitro percent TRH release and in vivo percent absorption of TRH from optimized formulation

\begin{tabular}{llcccc}
\hline \multicolumn{1}{c}{ Time $(\mathrm{h})$} & 0 & 2 & 4 & 6 & 8 \\
\hline In vitro release $F_{\mathrm{r}}(\%)$ & 0 & 15.245 & 34.385 & 53.665 & 70.234 \\
In vivo absorption $F_{\mathrm{a}}(\%)$ & 0 & 31.431 & 68.675 & 96.642 & 100.801 \\
\hline
\end{tabular}

$F_{\mathrm{r}}$ - drug fraction release

$F_{\mathrm{a}}$ - drug fraction absorbed

\section{CONCLUSIONS}

Extended release formulations of TRH were developed based on osmotic technology. The effect of different formulation variables was studied to optimize the release profile. Drug release was directly proportional to the level of plasticizer, but inversely related to the level of swellable polymer and membrane thickness. Release from the developed formulations was independent of $\mathrm{pH}$ and agitation intensity of the release media, assuring the release to be fairly independent of $\mathrm{pH}$ and hydrodynamic conditions of the absorption site. TRH release from the developed formulations was inversely proportional to the osmotic pressure of the release media, confirming osmotic pumping to be the major mechanism of drug release. The in vivo study showed that the optimized formulation (batch IV) achieved a higher value of $A U C_{0-24}$, relative bioavailability and $M R T$ compared to the commercial formulation of TRH. This study suggests that the developed optimized formulation (IVB) could perform therapeutically much better than the commercial immediate release (M1) and sustained release (M2) tablets of TRH as potential prolonged and controlled release dosage forms. 
P. Kumar et al.: Development and biopharmaceutical evaluation of extended release formulation of tramadol hydrochloride based on osmotic technology, Acta Pharm. 59 (2009) 15-30.

\section{REFERENCES}

1. H. W. Hui, J. R. Robinson and V. H. L. Lee, Design and Fabrication of Oral Controlled Release Drug Delivery Systems, in Controlled Drug Delivery: Fundamentals and Applications (Eds. J. R. Robinson and V. H. L. Lee), $2^{\text {nd }}$ ed., Marcel Dekker, New York 1987, pp. 373-374.

2. R. K. Verma, B. Mishra and S. Garg, Osmotically controlled oral drug delivery, Drug Dev. Ind. Pharm. 26 (2000) 695-708; DOI: 10.1081/DDC-100101287.

3. M. Speers and C. Bonnano, Economic Aspects of Controlled Drug Delivery, in Encyclopedia of Controlled Drug Delivery (Ed. E. Mathiowitz), Wiley, New York 1999, pp. 341-347.

4. R. K. Verma, D. M. Krishna and S. Garg, Formulation aspects in the development of osmotically controlled oral drug delivery systems, J. Control. Rel. 79 (2002) 7-27; DOI: 10.1016/j.conrel.2003.09.009.

5. F. Theeuwes, Elementary osmotic pump, J. Pharm. Sci. 64 (1975) 1987-1991; DOI: 10.1002/jps. 2600641218.

6. P. Kumar, S. Singh, P. S. Rajinikanth and B. Mishra, An overview of osmotic pressure controlled release formulation, J. Pharm. Res. 5 (2006) 34-45.

7. P. Kumar and B. Mishra, An overview of recent patents on oral osmotic drug delivery systems, Recent Patents on Drug. Del. Form. 1 (2007) 236-255; DOI: 10.2174/187221107782331638.

8. S. A. Schug, Tramadol in acute pain, Acute Pain 5 (2003) 1-3; DOI: 10.1016/S1366-0071(03) 00028-7.

9. C. Mattia and F. Coluzzi, Once-daily tramadol in rheumatological pain, Expert. Opin. Pharmacother. 7 (2006) 1811-1815; DOI: 10.1517/14656566.7.13.1811.

10. S. B. Tiwari, K. Murthy, M. R. Pai, P. R. Mehta and P. S. Choudhary, Controlled release formulation of tramadol hydrochloride using hydrophilic and hydrophobic matrix system, AAPPS Pharm. Sci. Tech. 4 (2003) 1-6.

11. P. Kumar, S. Singh and B. Mishra, Gastroretentive drug delivery system of ranitidine hydrochloride based on osmotic technology: development and evaluation, Curr. Drug Del. 5 (2008) 332-342; DOI: 10.2174/156720108785914943.

12. J. Shokri, P. Ahmedi, P. Rashidi, M. Shahsavri, A. R. Siahboomi and A. Nokhodchi, Swellable elementary osmotic pump (SEOP): An effective device for delivery of poorly water soluble drugs, Eur. J. Pharm. Biopharm. 68 (2008) 289-297; DOI: 10.1016/j.ejpb.200706.006.

13. United States Pharmacopoeia 30, National Formulary vol. 1, USP Convention, Rockville 2007.

14. C. Aguzzi, M. C. Bonferoni, M. R. Osorio, F. S. Rossi, F. Ferrari and C. Caramella, Influence of complex solubility on formulations based on lambda carrageenan and basic drugs, AAPPS Pharm. Sci. Tech. 3 (2002) 1-7.

15. M. R. Rouini, Y. H. Ardakani, F. Soltani, H. Y. Aboul-Enein and A. Foroumadi, Development and validation of rapid HPLC method for simultaneous determination of tramadol and its metabolites in human plasma, J. Chromatogr. B. 830 (2006) 207-211; DOI: 10.1016/j.jchromb.2005.10.039.

16. A. Kucuk, Y. Kadioglu and F. Celebi, Investigation of the pharmacokinetics and determination of tramadol in rabbit plasma by a high-performance liquid chromatography-diode array detector method using liquid-liquid extraction, J. Chrom. B. 816 (2005) 203-208; DOI: 10.1016/j.jchromb. 2004.11.031.

17. P. Costa and J. M. S. Lobo, Modeling and comparison of dissolution profiles, Eur. J. Pharm. Sci. 13 (2001) 123-133; DOI: 10.1016/S0928-0987(01)00095-1.

18. B. Mishra, B. V. Bakde, P. N. Singh and P. Kumar, Development and in-vitro evaluation of oral sustained release formulation of tramadol hydrochloride, Acta Pharm. Sci. 48 (2006) 153-166.

19. X. Li, W. Pan, S. Nie and L. Wu, Studies on controlled release effervescent osmotic pump tablets from traditional Chinese medicine compound recipe, J. Control. Rel. 96 (2004) 359-367; DOI: 10.1016/j/jconrel.2004.01.026. 
P. Kumar et al.: Development and biopharmaceutical evaluation of extended release formulation of tramadol hydrochloride based on osmotic technology, Acta Pharm. 59 (2009) 15-30.

20. N. Sinchaipanid, S. Pongwai, P. Limsuwan and A. Mitrevej, Design of salbutamol EOP tablets from pharmacokinetic parameters, Pharm. Dev. Technol. 8 (2003) 135-142; DOI: 10.1081/PDT-120018479.

21. F. Musshoff and B. Madea, Fatality due to ingestion of tramadol alone, Forensic Sci. Int. 116 (2001) 197-199; DOI: 10.1016/s0379-0738(00)00374-1.

22. A. M. Razaghi and J. B. Schwartz, Investigation of cyclobenzaprine hydrochloride release from oral osmotic delivery systems containing a water swellable polymer, Drug Dev. Ind. Pharm. 28 (2002) 631-639; DOI: 10.1018.DDC-120003855.

23. A. M. Razaghi and J. B. Schwartz, Release of cyclobenzaprine hydrochloride from osmotically rupturable tablets, Drug. Dev. Ind. Pharm. 28 (2002) 695-701; DOI: 10.1081/DDC-120003861.

24. ICH Q1A (R2), Stability Testing Guidelines: Stability Testing of New Drug Substances and Products, EMEA, London 2003.

$S A \check{Z} E T A K$

\section{Razvoj i biofarmaceutsko vrednovanje pripravaka za povećano oslobađanje tramadol hidroklorida na principu osmotske tehnologije}

PRAMOD KUMAR, SANJAY SINGH i BRAHMESHWAR MISHRA

U radu je opisana priprava i evaluacija pripravaka tramadol hidroklorida (TRH) na principu osmotske tehnologije. Da bi se postigao željeni profil oslobađanja mijenjane su različite varijable. Pokazalo se da najveći utjacaj na oslobađanje ljekovite tvari imaju udjeli polimera koji bubri, plastifikatora i debljina ovojnice polupropusne membrane (SPM). TRH oslobađanje bilo je proporcionalno udjelu plastifikatora, a obrnuto proporcionalno udjelu polimera i vrijednosti SPM. Oslobađanje ljekovite tvari bilo je neovisno o $\mathrm{pH}$ i intenzitetu miješanja, a ovisno o osmotskom tlaku medija. $U$ in vivo studiji provedenoj na šest zdravih volontera određeni su farmakokinetički parametri $\left(c_{\max }, t_{\max }, A U C_{0-24}\right.$, $M R T)$ i izračunata relativna bioraspoloživost. Rezultati dobiveni u pokusima in vitro i in vivo uspoređeni su s dvije vrste komercijalno dostupnih tableta TRH: oslobađanje ljekovite tvari iz pripravka razvijenog u ovom radu bilo je dulje i više kontrolirano. In vitro-in vivo korelacija (IVIVC) je analizirana prema Wagner-Nelsonovoj metodi. Optimizirani pripravak (IVB) pokazao je dobru IVIV korelaciju $(R=0,9750)$. Proizvodni proces je bio reproducibilan i pripravci su bili stabilni tijekom 6 mjeseci u uvjetima ubrzanog starenja.

Ključne riječi: tramadol, povećano oslobađanje, osmotski tlak, polimer koji bubri, in vitro-in vivo korelacija

Department of Pharmaceutics, Institute of Technology, Banaras Hindu University, Varanasi-221005, U.P. India 